\title{
Nutrient intakes during early pregnancy of women living in Ireland
}

\author{
C. McGowan, J. Walsh, J. Byrne, M. Foley, R. Mahony and F. McAuliffe \\ School of Medicine and Medical Science, University College Dublin, National Maternity Hospital, Holles Street,
}

Dublin 2, Ireland

At no point in the life cycle is nutrition more important than before and during pregnancy. Diet is one of the major environmental factors influencing the development of the embryo and fetus, while maintaining maternal health ${ }^{(1)}$. Certain micronutrient deficiencies during pregnancy have been significantly associated with reproductive risks, including infertility and fetal structural anomalies ${ }^{(2-5)}$. Impaired growth and development in utero may 'programme' the fetus for developing metabolic diseases in adulthood ${ }^{(6)}$. Specific micronutrients also protect the mother from developing pregnancy-related disorders: sufficient calcium and magnesium reduces the risk of hypertensive disorders; adequate zinc reduces the risk of prematurity; increasing folic acid intakes prior to conception prevents neural tube defects, while increasing vitamin $B_{12}$ alongside folic acid prevents megaloblastic anaemia ${ }^{(7,8)}$. There is paucity in the literature surrounding the usual nutrient intakes of pregnant women in Ireland. The aim of the present study was to examine maternal nutrient intakes during early pregnancy of women in Ireland.

Two hundred and forty eight women were recruited from the antenatal clinic at the National Maternity Hospital in Dublin. Participants were considered for this study if they were between 10 and 18 weeks gestation, with a singleton pregnancy and adequate English. All participants completed a 3-d food diary in early pregnancy. It was requested that participants record in as much detail as possible their food and beverage intakes. Collected data were entered into NetWISP version 3.0 (Tinuviel Software, Llanfechell, Anglesey, UK) and statistical analysis was carried out in SPSS version 15.0 (SPSS Inc., Chicago, IL, USA).

Descriptive statistics showed that the mean daily intake of certain micronutrients were insufficient and did not meet current recommendations for pregnancy. The mean intake of folate was $272.9 \mu \mathrm{g}$ (SD 111.7), vitamin D was $2.6 \mu \mathrm{g}$ (SD 2.1), calcium was $880.6 \mathrm{mg}$ (SD 310.4) and iron was $11.1 \mathrm{mg}$ (SD 3.6). It was noted that only $2(0.8 \%)$ women met vitamin D recommendations, while only 20 (8.1\%) women met folate recommendations from diet alone. In contrast, the mean $\mathrm{Na}$ intake was $2671.8 \mathrm{mg}$ (SD 803.8) which is above the recommended allowance for the general adult population.

These data highlight the urgent need for public health interventions amongst pregnant women in Ireland. Fortification of foods with folic acid should be considered to increase maternal intakes and advocating peri-natal supplementation, particularly for vitamin D may be warranted.

1. Keen CL, Clegg MS, Hanna LA et al. (2003) J Nutr 133, 1597S-1605S.

2. McArdle HJ \& Ashworth CJ (1999) Br Med Bull 55, 499-510.

3. Ashworth CJ \& Antipatis C (2001) Reproduction 122, 527-535.

4. Black RE (2001) Br J Nutr 85, S193-S197.

5. Anderson HS, Gambling L, Holtrop G et al. (2006) J Nutr 136, 1171-1177.

6. Barker DJP, Gluckman PD, Godfrey KM et al. (1993) Lancet 341, 938-941.

7. Cetin I, Berti C \& Calabrese S (2010) Hum Reprod Update 16, 80-95.

8. West KP Jr, Katz J, Khatry SK et al. (1999) Br Med J 318, 570-575. 